\section{THE OCCURRENCE OF CYCLING INJURIES IN THE WESTERN PROVINCE: A DESCRIPTIVE STUDY}

\author{
by Bakkes ES, Hendry JA, Uys MS, \\ University of Stellenbosch
}

INTRODUCTION AND MOTIVATION

Descriptive studies are the natural precursor to other studies, and are essential in providing researchers with base-line information before more involved types of studies are embarked upon. Descriptive studies generally examine the occurrence and distribution of diseases or injuries according to group characteristics such as sex, race, age, socio-economic status or geographical distribution. An attempt is then made to explain the observed findings. This can aid in the identification of possible causal (aetiogical) factors, and frequently generates hypotheses for further study ${ }^{1}$. The lack of information regarding the occurrence of cycling injuries in South Africa, together with the increasing popularity of the sport, prompted this descriptive study.

The past two decades has seen a sharp increase in the popularity of both competitive and "fun" cycling ${ }^{2}$.

Cycling appears to be a relatively "safe" sport as there are no repetitive, high-impact, full-weightbearing movements involved, as is the case in running. The apparent safety of the sport prompts both medical and supplementary health professionals to encourage the use of cycling for the promotion and maintenance of health, as well as for rehabilitation purposes ${ }^{3,4}$. Sportsmen too, frequently use cycling for rehabilitation purposes following injury or operative procedures to the knee. Cycling injuries can be grouped into two main categories:

- Injuries related to falls, crashes, or collisions

- Injuries related to over-use ${ }^{5}$

Falls and accidents are regarded by some authors as the main cause of all cycling injuries ${ }^{6,7}$. However, over-use injuries, and in particular over-use injuries of the knee-joint, are of particular interest to many medical practitioners and physiotherapists. During steady cycling, forces equivalent to body weight are exerted on the pedals. During intermittent accelerations (eg. inclines, race start), these forces can exceed three times the body mass. More competent cyclists maintain a high tempo ("spin") of 80-100 revolutions per minute resulting in exceptionally fast alternating flexion and extension of the knee $^{6,8}$. Incorrect positioning of the cyclist can result in stressful forces being repeatedly exerted on the knee-joint. This may result in the incidence of new injuries, or the aggravation of underlying pathology.

\section{METHODOLOGY}

\section{Study design:}

In this descriptive study, the researchers examined the occurrence of cycling injuries over the 1 year period October 1988 to October 1989. The distribution of injuries according to cycling status (amateur/fun/serious) and registration with clubs and Pedal Power Associations was examined.

\section{Sampling:}

The population consisted of $3264 \mathrm{cy}$ clists who completed the Burger-Sanlam $100 \mathrm{~km} / 50 \mathrm{~km}$ race on 21 October 1989 . The sample consisted of 923 cyclists ( $28 \%$ ) randomly selected as they crossed the finishing line. Data on 21 cyclists was incomplete leaving a final study sample of 902 cyclists. Measurement:

Each subject was interviewed and information regarding the following was obtained:

- Personal data

- Cycling status (Amateur/professional/serious-fun/fun-rider)

- Membership with clubs/Pedal Power Associations

- Occurrence of injuries and falls (used synonymously with collisions and crashes) in the preceding 12 month period.

\section{RESULTS AND DISCUSSION:}

\section{Cycling status:}

The distribution according to cycling status can be seen in Figure 1 (page 63) which illustrates that the majority of $\mathrm{cy}$ clists $(852 / 923)$ were either fun- or serious fun-riders, with only a very small proportion (50/923) being classed as amateurs. These findings confirm the popularity of "fun" cycling". While this distribution may not necessarily reflect the proportions of cyclists (according to cycling status) of the total population who took part in the Burger/Sanlam race, it has been the authors' experience that the large number of funriders (52\%) is characteristic of the BurgerSanlam race. The total lack of participation by professional riders may be due to the Rapport cycle tour running concurrently.

In South Africa there are only a small handful of highly-competitive cyclists (amateurs) who are registered with the SA Cycling Federation. It was therefore expected that they would be out-numbered by the serious fun-riders ( $5 \%$ vs $40 \%$ ). The status of 21 cyclists could not be determined and these cyclists were excluded from further study.

\section{ABSTRACT}

:On 21 October 1989, a total of 902 randomly selected cyclists were questioned at the finish of the Burger-Sanlam $100 \mathrm{~km} / 50 \mathrm{~km}$ race to determine the prevalence of cycling injuries in the preceding year. Of the total sample 551 cyclists $(61 \%)$ reported they had been injuryfree during the 12 month period prior to the investigation. The remaining 351 cyclists had sustained a total of 681 injuries during the same period ie approximately 2 injuries per cyclist per year.

The most commonly reported injuries were over-use injuries resulting in pain and discomfort in the back and neck regions $(41 \%)$, with pain in the knee joint being the second most Irequently reported injury (29\%).

This descriptive study has provided valuable base-line information on the types and frequency of injuries sustained by South African cyclists. In particular, the high number of overuse injuries associated with faulty ergonomics has generated hypotheses for further study. An intimate knowledge of the ergonomics related to the sport, as well as attention to educational programmes is also strongly indicated.

\section{ABSTRAK}

Op 21 Oktober 1989 is ' $n$ totaal van 902 fietsryers, wat ewekansig gekies is, aan die einde van die Burger-Sanlam $100 \mathrm{~km} / 50 \mathrm{~km}$ wedren ondervra, om die prevalensie van fietsrybeserings die afgelope jaar te bepaal. Van die hele steekproef was 551 fietsryers (61\%) die voorafgaande jaar besering-vry. Die oorblywende 351 fietsryers het 'n totaal van 681 beserings in dieselfde tydperk gehad D.w.s. ongeveer 2 beserings per fietsryer per jaar.

Beserings wat mees algemeen voorgekom het was oorbruiksbeserings met gevolglike pyn en ongemak in the rug en nek areas ( $41 \%)$, met pyn in die knie-gewrig as die tweede mees algemene klagte $(29 \%)$. Die beskrywende studie het waardevolle inligting aangaande die tipes en frekwensie van beserings onder Suid Afrikaanse fietsryers verskat. Veral die hoë aantal oorbruiksbeserings wat met foutiewe ergonomika geassosieer was het hipoteses vir verdere studie gegenereer.

Indiepte kennis van die ergonomika van die sportsoort en opvoedkundige programme word beslis aanbeveel.

\section{Registration status:}

All 50 amateur (100\%) were members of a cycling club or Pedal Power Associatoni (PPA) in comparison with only $70 \%$ of the serious fun-riders and $36 \%$ of the fun riders. Club membership is compulsory for all amateurs, while membership of a PPA is optional. This would explain the high proportion of amateur cyclists in this category.

The percentage of fun-riders who are members of an organised body (like a PPA) is low $(36 \%)$. PPA's are regionally organised and ensure a good standard of organisation, safe routes and the strategic

continued on page 63. . 
E.M.G. MYOTRAC \& MYODAC 2 As used in McConnell Technique Palm sized EMG for clinical use

Strengthening Rehabilitating Relaxing Work simulation monitoring
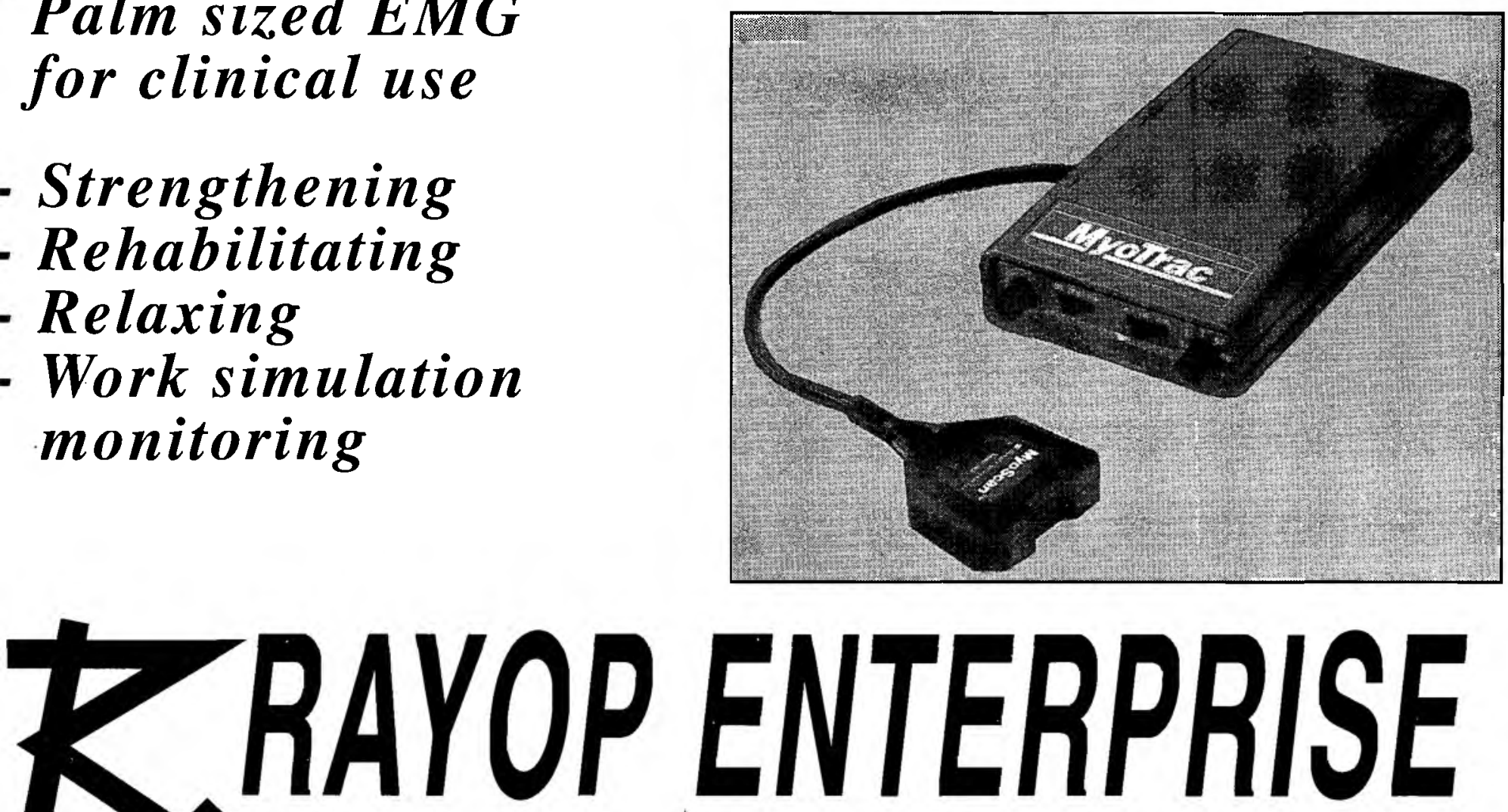

P. O. Box 554 Rondebosch 7700 TEL: (021) 61-8066

ThermiPaq'S Ceramic packs Hot/Cold Transfer Technology

Dual use

Freezer to Microwave

Dry or Moist heat therapy

Outperforms competitor products

Standard 2 Treatment level cover and double sided

Velcro strap

Also available: Compact TENS, Electrodes, Interferential, Ultrasound, etc.

$6^{\mathrm{r}} \times 12^{\mathrm{I}}$ Thermipaq performance

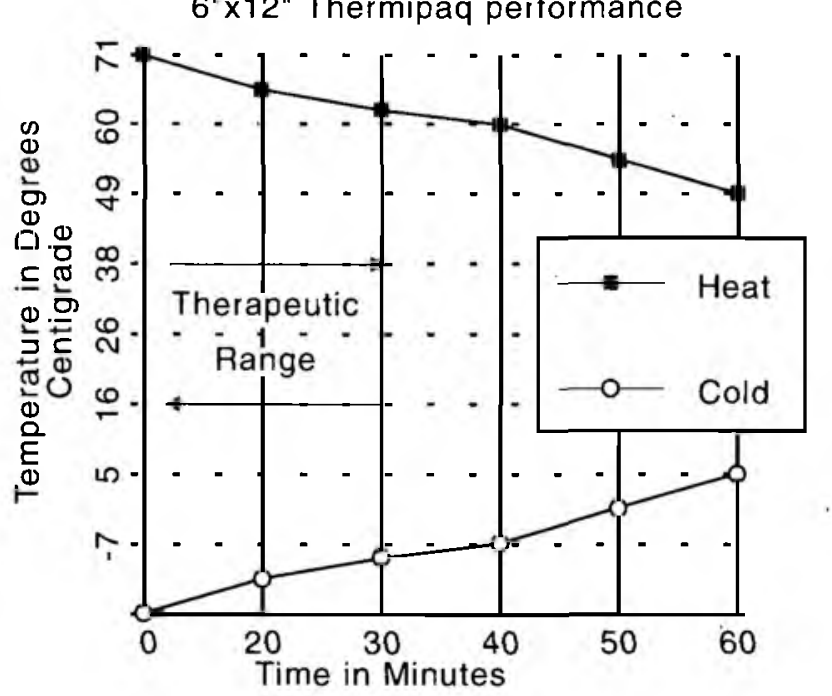


.continued from page 61

placement of water tables. PPA's also publish a newsletter which could inform the cyclist about scientific training methods and the causes and treatment of injuries. Membership of a PГA would therefore presuppose a relatively high level of education of the cyclist and a correspondingly low prevalence of injuries. However, a study of the Western Province magazine Life Cycle shows that the content is largely comprised of readers opinions, race criticisms and articles on the wearing of helmets. There are few articles on the causes and treatment of injuries, and no articles on the importance of correct ergonomics with a view to the prevention of injuries.

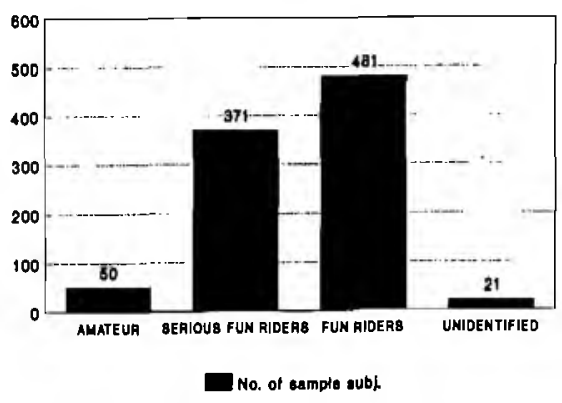

Figure 1: Sample distribution

As only $36 \%$ of the fun-riders group were members of cycling clubs or PPA's, the authors expected the occurrence of injuries amongst the fun-rider group to exceed that of the other two groups.

Occurrence of injuries: General

The types and frequency of injuries as reported by the 902 sample subjects for the 12-month period October 1988 October 1989 can be seen in Table 1.

TABLE 1: The occurrence of injuries in all cyclists: October 1988 October 1989

\begin{tabular}{|l|l|l|}
\hline & NUMBER & PERCENT \\
\hline Injury-free & 551 & 61 \\
\hline Falls & 134 & 19,8 \\
\hline Knee pain & 195 & 18,6 \\
\hline Pain/dicomfort & 281 & 41,3 \\
\hline Muscle & 32 & 4,7 \\
\hline Other & 39 & 5,7 \\
\hline
\end{tabular}

Table 1 indicates that more than half the total group (61\%) were injury-free during the preceding 1 year period. Pain and discomfort, excluding pain in the knee-joint, was most frequently reported $(41 \%$ of all injuries). Pain in the knee-joint was the second most frequently reported injury (29\% of all injuries), with "falls" (which included crashes, collisions or accidents) being the third most frequently reported injury ( $20 \%$ of all injuries).

It was postulated that the more serious the level of competition, the higher the proportional increase in injuries. An examination of the percentage of injuries for each of the different cycling status groups is given in Figure 2.

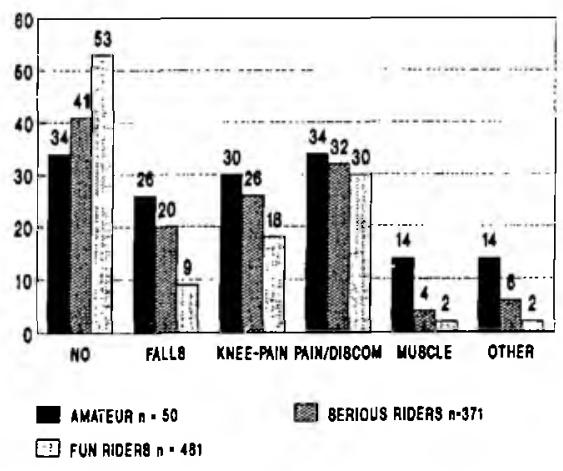

Figure 2: Occurrence of inuries: percentage per group

The proportions of cyclists who reported being injury free during the preceding 12 -month period varied from $34 \%$ $(17 / 50)$ for the amateur cyclists, to $41 \%$ for the serious fun-rider group (152/371) and $53 \%$ for the fun-rider group $(255 / 481)$. If one examines the distribution of cyclists sustaining injuries in each of the different groups, the percentage of amateur cyclists sustaining injuries exceeds that of the serious-fun and fun-rider groups for all types of injuries.

The large proportion of amateur cyclists who sustain injuries may be attributed to factors such as high speeds, increased aggression, and increased time and intensity of training. Serious fun-riders are less competitive than amateurs and cycle for individual performance, while fun-riders cycle merely for pleasure.

While 523 cyclists reported being injury-free during the preceding 12 -month period, the remaining 379 subjects reported a total of 681 injuries during the same period.

While $34 \%$ of amateurs in this study, who made up the smallest group, experienced some degree of pain or discomfort this comprises only $3 \%$ of the total number of injuries. This is in marked contrast with the other two groups (serious-fun and funriders), where pain and discomfort comprised $18 \%$ and $21 \%$ of all injuries respectively. While physiotherapists may, therefore, treat injuries sustained by highly competitive amateur cyclists, they can expect to see large numbers of injuries from the other two categories of cyclists as well Occurrence of injuries: Specific

In this study, falls were the third most frequently reported injury, and comprised $20 \%$ of all injuries (See Table 1). This is in contrast with Town (1985) who regards falls as "the most important source of injuries amongst cyclist" ${ }^{\prime 7}$. The percentages of falls in this study is higher than the prevalence of $13 \%$ as reported by Kruze et $a l^{10}$, whose study sample consisted of 528 students who cycled for sport, recreation or competitive reasons. (The samples in these two studies are therefore comparable.)

The percentage of reported falls per cycling status group was:

- amateurs (26\%)

- serious fun-riders $(20 \%)$

- fun-riders $(9 \%)$

The low number of falls reported in the fun-rider group may be attributed to several possible factors such as lower speeds, less competitiveness and aggression, and fewer hours and kilometers on the cycle.

The percentage of falls reported by the amateur cyclists in this study (26\%) is markedly higher than the $3.2 \%$ as reported by McLennan et al (1988) whose study sample consisted only of amateurs ${ }^{9}$. This finding may be a reflection of the inexperience of our a ma teur cyclists due to lack of international competition, or the fact that prior to this study, little or no seeding was done in most cycle races.

McLennan et al (1988) report that the prevalence of falls in the USA was reduced from $3.2 \%$ to $1.5 \%$ after a four-year period during which an injury-prevention programme was implemented ${ }^{9}$. In comparison with this reduced percentage, South African cyclists appear to have a much higher frequency of falls when compared to their American counterparts ie., a seventeen-times higher occurrence of falls. Of even greater concern is the fact that all of the falls reported in McLennan's study occurred during races held at 1,500 metres above sea-level, where acute mountainsickness (which impairs concentration and reflexes) plays a major causative role in the incidence of falls 9 . It is evident from the results in this study that there is a need to increase the standard and safety of all aspects of cycling in South Africa. Clubs and PPA's could play an important and active role in this respect.

The injuries sustained from falling can be divided into minor and major injuries. Minor injuries:

Bruises and abrasions: The three categories of riders showed no marked differences with regard to minor injuries sustained, with the frequency of bruising ranging from $92 \%$ in the amateur group to $95 \%$ in the fun-rider group. Abrasions occurred less frequently, varying from $31 \%$ $35 \%$ in the three groups. Ballham et al (1988) on the other hand, reported a much higher occurrence of abrasions $(46.7 \%)$ occurring amongst a group of cyclists of mixed cycling status ${ }^{12}$. This is slightly higher than the percentage found in this study. It is possible that the percentage in this study is an under-estimation, as it became apparent, while interviewing sample subjects, that many did not regard bruises and abrasions as "injuries".

Major injuries:

Fractures: The amateur riders in this study had a $23 \%$ occurrence of fractures as 
a result of falls. This is slightly lower than the $49.3 \%$ amongst American amateurs as reported by McLennan et al $(1988)^{9}$. The apparently higher proportion of fractures in the American study should, however, be compared with caution, as the sample size was very large ( $n=5482$ ) and all falls had occurred in races exceeding 1500 metres above sea-level.

In this study $16.5 \%$ of the serious funrider and fun-rider groups sustained fractures, which is comparable with the findings of Tucci and Barone (1988) and Biburz et al (1986) of $20 \%$ and $14.1 \%$ respectively $^{11,2}$.

Dislocations and sprains: Only $6 \%$ of cyclists sustained a dislocation or sprain as a result of a fall.

Head injuries: In South Africa the wearing of helmets is optional, although it may be a pre-requisite for participation in certain competitions. In this study $8.2 \%$ of cyclists reported suffering a head injury after falling. McLennan et al(1988) reports a prevalence of $15 \%$ decreasing to $0 \%$ after the successful implementation of an accident-prevention programme and the introduction of legislation enforcing the wearing of helmets of a specified safety standard ${ }^{9}$. In view of the possible severity of this type of injury, it would appear that South Africa has a definite need for the implementation of similar precautionary measures. In addition, educational programmes regarding road safety, ensuring the good mechanical functioning of cycles and other safety measures (such as the wearing of protective clothing; teaching cyclists how to slip, fall, slide etc) are imperative.

\section{Areas of pain and discomfort (knee joint} excluded):

It can be seen from Figure 2 that there was an almost equal distribution of reports of pain and discomfort among the three groups of cyclists $(30 \%-34 \%)$. Most cyclists are likely to experience some degree of pain or discomfort, particularly when unfit or cycling long distances. The degree of pain and discomfort may be further increased if positioning on the cycle is faulty or the wrong equipment is used.

More than half of the cyclists in each of the three groups experienced pain or discomfort in the back and neck regions. This is frequently due to the sustained position of flexion on the cycle, faulty ergonomics, poor training techniques and/or weak abdominal and /or back musculature. By correcting the positioning on the cycle, strengthening the trunk musculature, and regularly stretching the neck and lower back, these symptoms can be prevented ${ }^{6,13,5,14}$. It is therefore important for the physiotherapist to give attention to the latter problems (including an examination of the cyclist on his cycle) rather than just treat the presenting complaints symptomatically.
Pain and discomfort in the buttocks was most evident in the fun-rider group and was probably due to their being unaccustomed to the long distance of between $50 \mathrm{~km}-100 \mathrm{~km}$ they had just completed. Relief can be found by correct positioning, regular training and the correct saddle size.

According to Noakes et al (1990), van Velden et al (1990) and Bohlman JT (1981), pain and discomfort in the hands is a common problem of cyclists ${ }^{15,3,6}$. In contrast with their findings, however, only $3.2 \%$ of the cyclists in this study reported this complaint. Pain and discomfort in the upper limb region can be further minimised by correct positioning with resultant improved weight-distribution, frequent changes of hand position and an improved level of fitness.

Muscle injuries did not feature as prominently as was expected. Only $2.5 \%$ of all injuries fell into this group. Seven of the amateur riders experienced serious muscle injuries in comparison with only 15 cyclists in the serious- and 10 cyclists in the funrider groups.

Although not as competitively inclined as the amateurs, the serious- and fun-rider cyclists still form a sizeable group who may require the intervention of a physiotherapist in order to prevent a recurrence of the injury. In this study, muscle tears and tendinitis occurred equally frequently

The occurrence of dehydration, hypothermia and hyperthermia ranged from $14 \%$ in the amateurs to $2 \%$ in the fun-rider group. The high summer temperatures in South Africa, during which most of the competitions take place, again highlights the urgent need for adequate education of cyclists to increase their awareness of these potential problems.

\section{Pain and discomfort in the knee joint:}

Of all the cyclists in this study $21.6 \%$ reported having experienced pain or discomfort in the knee-joint in the preceding 12-month period (See Table 1). Thirty percent of the amateurs, $26 \%$ of the serious fun-riders and $18 \%$ of the fun-riders had been afflicted by knee pain (See Figure 2). A subsequent investigation of this group showed that in $80 \%$ of the cases this pain resulted from incorrect ergonomic adjustments leading to an incorrect critical knee angle. The critical knee-angle is defined as follows:

With the cranks in the horizontal position, a perpendicular line, which falls just posterior to the patella of the knee joint, should fall through the ball of the foot and the axle of the pedal, or as close as possible to it.

It has been the author's observation that fun-riders often train irregularly. They possibly also run the highest risk of having ergonomic faults with regard to framesize, saddle-height and positioning on the cycle. However, contrary to expectations, the percentage of knee-pain experienced in this group was the lowest. However, as fun-riders generally follow a training programme of low intensity, the effect of ergonomic faults which may have contributed to the development of knee-pain, could well have been obscured.

The occurrence of knee-pain amongst the a mateurs was high (30\%), and could be due to over-use and/or faulty ergonomics. More than half the cyclists experiencing knee-pain were members of PPA's. Therefore, although these cyclists have access to clubs, trainers, and possibly the newest information regarding training methods, it would appear that little information from PPA newsletters regarding correct ergonomics is conveyed, or if so, successfully reaches its target group.

In the light of these findings, it is imperative for physiotherapists treating cyclists with symptoms of knee-pain to refrain from treating purely symptomatically. An examination of the cyclist on his bike, to ensure that the critical knee-angle is correct, must be included in the rehabilitation programme. This is further emphasised when it is considered that sixty cyclists in this group had suffered previous injury or surgery to the knee-joint. They had started cycling on the recommendation that it was a relatively "safe sport" and ideal for rehabilitation purposes. In the case of these cyclists a very careful examination is needed to distinguish between the prior knee injury and incorrect ergonomics as the cause of their knee pain.

\section{CONCLUSION}

The above descriptive study has examined the occurrence of injuries in a select sample of cyclists who participated in the Burger-Sanlam race in October 1989. Although $61 \%$ of the subjects reported that no injuries had been sustained in the preceding 12-month period, a total of 681 injuries were reported. Pain and discomfort in the back and neck regions were most common, with pain in the knee-joint being the second most frequently reported injury.

The percentage of cyclists reporting injuries over the preceding 12-month period was lowest in the fun-rider group. The percentage of falls experienced by all groups of riders was high, and indicates the need for the implementation of accident-prevention and educational programmes. Pedal Power Associations and clubs should play a more dynamic and educational role with regard to the causes and prevention of injuries. Legislation to enforce the compulsory wearing of helmets is also strongly indicated.

Cyclists should be made aware of the importance of correct positioning in order to prevent over-use injuries particularly of 


\section{THE PREVALENCE OF LOW BACK PAIN IN CRICKETERS - AN UNDERGRADUATE EPIDEMIOLOGICAL STUDY}

\author{
by Ian Harris, Dept of Physiotherapy, \\ University of Cape Town
}

\section{INTRODUCTION}

Cricket in South Africa plays a major socio-economic role and, through innovations such as the one day limited overs and day-night games, is increasingly drawing the attention of large crowds throughout the country.

Cricket is becoming far more aggressive and faster ${ }^{3}$ and is placing greater strains on thecricketer's body. The lumbar area of the cricketer is one of the areas that is being placed under increased strain, especially in the fast bowling action ${ }^{2}$. This is taking place at a time when, with increased professionalism, cricketers can least afford to be affected by disabling injuries, such as Low Back Pain (LBP).

LBP in itself has far reaching affects on the general community with as much as $5 \%$ of all time absent from work being attributed to $\mathrm{LBP}^{3}$. With the added stresses and strains of modern cricket, epidemic levels of LBP are expected amongst cricketers. The problem of LBP is further aggravated by the difficulty of making an accurate diagnosis. LBP is often characterised by the stooped appearance associated with old age which could be harmful to the self esteem of a cricketer with LBP. Therefore, LBP is not frequently discussed by the cricketing fraternity, making it extremely difficult to ascertain the true extent of LBP in cricketers.

The dearth of research on cricket in South Africa and the changing nature of the game challenges science and medicine to explore the various aspects of the game.

\section{METHOD}

A questionnaire was given directly to 110 cricketers, 55 from the first teams of

\section{continued from page 64}

the knee-joint. Physiotherapists treating cycling-related injuries should not treat purely symptomatically, and a thorough knowledge of the above-mentioned factors is imperative. The distinguishing trademark of the effective practitioner in this case will not be her knowledge of physiotherapy, but her knowledge of the sport.

\section{REFERENCES}

1. Friedman GD. Primer of Epidentiology 1980. McGraw Hill, New York

2. Kiburz Z, Jacobs R, Reckling F et al. Bicycle Accidents and Injuries among Adult Riders. five cricket clubs and from five schools in the Western Cape during the 1991/92 season. The questionnaire consisted of an initial set of close-ended questions as well as a further set of open-ended questions which allowed the respondents to voice their opinions.

A grading scale of pain severity was used to measure LBP. The pain being graded as follows: Grade 1, an ache but could continue playing, Grade 2, pain which forced the player to leave the field and Grade 3, pain which prevented the playing of a match. Each respondent was classified as either a fast bowler (FB), slow bowler (SB), batsmen (BAT) and a wicket keeper (WK).

Numerous cricket practices and matches were visited in order to gain general information on warm-up methods, different techniques shown and to obtain a feel for the cricketers' personalties and idiosyncrasies.

The data obtained from the questionnaire was presented by means of descriptive statistics with null hypotheses being formulated and tested by appropriate statistical tests.

\section{RESULTS}

The return response was $90 \%$. The mean age was 20.2 years with a range of between 15 and 35 years, with $55.6 \%$ of respondents being above 18 years old and $44.4 \%$ were younger than 18 years. The mean number of years playing cricket was 12.3 years with a range between 3 and 27 . The respondents consisted of $37.4 \% \mathrm{FB}, 58,6 \% \mathrm{BAT}, 27.3 \%$ SB and $11.1 \%$ WK.

\section{PREVALENCE OF INJURY}

LBP was present in $61.6 \%$ of the cricketers and, of these, $78,7 \%$ cited cricket as being the cause of the LBP.

\section{SEVERITY OF INJURY}

Grade 1 injuries were most prevalent (72.1\%), although Grade 3 injuries oc-

Am Jnl Sports Med 1986;14(5):416-419.

3. van Velden DP, Roberts T, Human E et al. Fietsry vir Almal (1st Ed.) 1990. Tafelberg Uitgewers, Kaapstad.

4. McLeod WD, Blackburn TA. Biomechanics of Knee Rehabilitation with Cycling. Am Inl Sports Med 1980;8(3):175-180.

5. Reilly T. Sports Fitness and Sports Injuries (3rd Ed.) 1981. Faber \& Faber, London.

6. Bohlman JT. Injuries in Competitive Cycling. The Phys \& Sports Med 1981;9(5):117-126.

7. Town GP. Science of Triathlon Training and Competition (1st Ed.) 1985. Human Kinetics Publishers, Champaign, Illinois.

8. Hannaford DR, Moran GT, Hlavad HF. Video Analysis and Treatment of Over-use Kneè Injury in Cycling: A Limited Clinical Study Clin in Podiatric Med and Surg 1986;34:671678.

\section{ABSTRACT}

The prevalence of Low Back Pain (LBP) in cricketer's was determined and possible causative factors were investigated. Questionnaires were sent to 110 cricketers playing for their first times of both clubs and schools during the $1991 / 92$ season. The return response was $90 \%$ with a prevalence of LBP at $61.6 \%$. Of these $78.7 \%$ cited cricket as being the primary cause of their LBP. The injuries were predominantly grade $1(72.1 \%)$, lollowed by grade 3 $(23.1 \%)$ and grade $2(6.6 \%)$. Grading was made according to the effect the pain had on the cricketers game. Fast bowlers proved to be more al risk of developing LBP with a group prevalence of $75.6 \%$ followed by wicket keepers at $63.6 \%$, batsmen at $56.8 \%$ and slow bowlers at $48.1 \%$. Cricketers had rather a poor general knowledge of ways of protecting their backs. Recommendations were made to help reduce the high prevalence of LBP, especially amongst Fast bowlers and in cricketers in general.

curred in a large group (21.3\%). A further indicator of severity is the large number $(62.3 \%)$ of cricketers who required treatment for their LBP.

\section{GROUP PREVALENCE}

The largest proportion of LBP was amongst the fast bowlers $(75.6 \%)$ which proved to be statistically significant with an obtained p-value of 0.06 using the Chisquared test. Furthermore, it was found that there was a higher prevalence of LBP in FB's with a front-on action (85.7\%) than in those with a side-on action $(72.4 \%)$. The group of front-on bowlers was too small for statistical testing.

\section{OTHER FACTORS}

Of the factors investiga ted (age, number of years playing, warm-up, various types of exercises, knowledge of prevention of injuries), the only one that proved to be significant was the lack of knowledge that cricketers had of ways to protect their backs. Of those cricketers who had LBP, only $55.7 \%$ said they knew how to protect their backs. Age did not prove to be a significant predictor of LBP.

9. McLennan JG, McLennan JC, Ungersma J. Accident Prevention in Competitive Cycling Am Jnl Sports Med 1988:16(3):266-273.

10. Kruze DL, McBeath AA. Bicycle Accidents and Injuries Am Inl Sports Med 1980;8:342344.

11. Tucci JJ, Barone JE. A Study of Urban Bicycling Accidents Am Inl Sports Med 1988;16(2):181-184.

12. Balham A, Absoud Em, Kotecha MB. A Study of Bicycle Accidents Injury Am Jnl Sports Med 1988;16(6):405-408.

13. Malhoney F. Bicycling Magazine's complete Guide to Riding and Racing Techniques. 1979.

14. Dubb I, Jacobs L, Sutton P. Injuries in $\mathrm{Cy}$ clists. Physio Forum 1989;3/90:12.

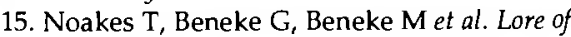
Cycling 1990. Oxford University Press, Cape Town. 